\author{
И. Н. Колядко \\ Белорусский государственный университет
}

\title{
КУЛЬТУРНАЯ ТРАДИЦИЯ И КРИЗИС ЛЕГИТИМАЦИИ В РАЗВИТИИ СОЦИАЛЬНОЙ СИСТЕМЫ: РЕЦЕПЦИЯ МЕТАМОДЕРНА
}

Одним из главных вызовов для развития социальной системы в условиях деформации ее фундаментальных оснований и перехода к новому порядку является кризис легитимации. Легитимность, в свою очередь, опирается на санкционированный культурной традицией ценностно-нормативный инвариант, задающий параметры социального порядка. Признание культурных универсалий ценностями, образующими базисные параметры интегративного качества социальной системы, представляет собой процесс легитимации - установления власти как средства поддержания и воспроизводства социального порядка. При этом идеология полагает ценности-нормы, упорядочивающие социальное взаимодействие. В трансформирующемся социуме ввиду отсутствия признанной в качестве легитимной системы ценностей одним из способов осуществления власти и поддержания порядка выступает манипулирование.

Актуальный кризис легитимации, порождающий конфронтацию социальных сил в обществе, разрешается путем достижения согласия («гегемонии» в терминологии А. Грамши). Заново истолкованные культурные универсалии, фундирующие основание «картины социальной реальности», в метамодерне выступают в качестве взаимодополняющих, равно претендующих на признание их легитимными. В таком случае смена мировоззренческих парадигм в ходе «пассивной революции» предстает как процесс фрагментации «коллективной воли», что чревато опасностью возрастания фундаментализма и экстремизма.

Ключевые слова: социальная система, культурная традиция, власть, ценностно-нормативная система, социальный порядок, метамодерн.

Для цитирования: Колядко И. Н. Культурная традиция и кризис легитимации в развитии социальной системы: рецепция метамодерна // Труды БГТУ. Сер. 6, История, философия. 2021. № 1 (245). C. $155-160$.

\author{
I. N. Kolyadko \\ Belorussian State University
}

\section{CULTURAL TRADITION AND THE CRISIS OF LEGITIMATION IN THE DEVELOPMENT OF THE SOCIAL SYSTEM: RECEPTION OF METAMODERN}

One of the main challenges for the development of a social system in the face of the deformation of its fundamental foundations and the transition to a new order is the crisis of legitimation. Legitimacy, in turn, rests on the value-normative invariant sanctioned by the cultural tradition, which sets the parameters of the social order. The recognition of cultural universals as values that form the basic parameters of the integrative quality of the social system is a process of legitimation, the establishment of power as a means of maintaining and reproducing social order. At the same time, ideology assumes values-norms that order social interaction. In a transforming society, due to the absence of a recognized system of values as legitimate, one of the ways to exercise power and maintain order is manipulation.

The current crisis of legitimation, giving rise to a confrontation of social forces in society, is resolved by reaching agreement ("hegemony" in the terminology of A. Gramsci). The newly interpreted cultural universals that underpin the "picture of social reality" in metamodernism act as complementary ones, equally claiming to be recognized as legitimate. In this case, the change in worldview paradigms in the course of the "passive revolution" appears as a process of fragmentation of the "collective will", which is fraught with the danger of an increase in fundamentalism and extremism.

Key words: social system, cultural tradition, power, value-normative system, social order, metamodern.

For citation: Kolyadko I. N. Cultural tradition and the crisis of legitimation in the development of the social system: reception of metamodern. Proceedings of BSTU, issue 6, History, Philosophy, 2021, no. 1 (245), pp. 155-160 (In Russian).

Введение. Социальная система в своем развитии сталкивается с вызовами, которые способны оказывать как деструктивное, так и конструктивно-созидательное влияние на ее базовые параметры и характеристики. Особую роль в поддержании социального порядка 
играет система ценностно-нормативных детерминант. Продуцируя присущие только человеческому обществу «искусственные формы социальности», такие как право, мораль, искусство, науку, она выступает своего рода «порождающим логосом», структурирующим социальное бытие и противостоящим «автоматически сцепившемуся ходу естественных событий», приводящему, как правило, к хаосу [1, с. 105-106]. Последний, в случае если приобретает стихийный, флуктуационный характер, при отсутствии механизмов рефлексивного управления способен оказать деструктивное воздействие на системную целостность, вплоть до процессов деструкции. Для социальных систем является характерным то, что порядок в них обеспечивается прежде всего посредством ценностно-нормативной, надбиологической регуляцией социальных процессов, протекающих в «искусственных формах социальной жизни» [1, с. 115]. М. Мамардашвили в «Вильнюсских лекциях по социальной философии» так поясняет эту особенность социальных систем: «В нормально развитых обществах характерно в общем господство искусственных форм; они находятся в сложном взаимодействии с элементарными формами, но тем не менее есть тенденция (оплаченная дорогой ценой - человеческими жертвами, страстями, борьбой) к тому, чтобы в целом общество регулировалось более или менее стержнем искусственных, культурных форм» [1, с. 115].

Основная часть. Социальный порядок конституируется посредством «“идей-ценностей”, структурирующих социальную связь» [2, с. 127], а кризис в развитии социальной системы возникает прежде всего как результат изменений иерархического статуса ценностно-смысловых констант и актуальных мировоззренческих парадигм, закрепленных в присущих конкретному обществу культурных универсалиях. В процессах трансформации ценностно-нормативной системы снижается эффективность регулирования социальных взаимодействий, что, в свою очередь, приводит к дезинтеграции социума и его подсистем, а также к стремительному расширению зон влияния маргинальных полей культуры. Кризис является специфической фазой в развитии социальной системы и характеризуется нарушениями в воспроизводстве норм социального порядка и деформацией целостности традиционных форм идентичности. В переломные эпохи развития деформации подвергается иенностно-нормативный инвариант, обеспечивающий соподчинение структурных уровней и устойчивость функционирования социальной системы. В результате увеличивается риск возникновения «редуцированных ситуаций, в которых срезаются искусственные формы социальности и остаются, выходят на поверхность и развертываются в бурной стихии элементарные формы» [1, с. 116], оказывающие репрессивное воздействие на процессы социогенеза и упорядочения.

Это обусловлено тем, что социальность как таковая представляет собой «мир людей и продуктов их совместной деятельности, обладающих неприродными и надприродными свойствами», а в роли субстанции социального выступает деятельность - «то “силовое поле”, которое продуцирует надорганическую форму существования, структурирует еe, определяет родовидовую специфику, формы и механизмы изменения» [3, с. 129-130]. В социальной системе социокод, аккумулирующий программы социального поведения, общения и деятельности, фиксируется и передается посредством культурной традиции. Средствами надбиологической (символической) регуляции жизнедеятельности людей она задает императивы развития и регулирует глубину эволюционных процессов системы с интенцией на сохранение ее целостности путем поддержания предельных значений интегративного качества. Одним из главных вызовов для развития социальной системы в условиях деформации ее фундаментальных оснований и перехода к новому порядку является кризис легитимации.

Прежде всего, необходимо выяснить, что следует понимать под легитимностью и легитимацией. Согласно определению «Новой философской энциклопедии», легитимность подразумевает «законность режима, политических деятелей и лидеров, отражает качества, вытекающие не из формальных законов и декретов, а из социального согласия и принятия их в качестве законных, т. е. соответствующих ценностным нормам со стороны самих граждан» [4, с. 384]. Так, конкретизируя понятие легитимности, Т. Парсонс обусловил устойчивость социальных систем способностью «актора реагировать на острые ситуационные требования, рассматриваемые либо как угрожающие, либо как благоприятные» [5, с. 31]. В понимании легитимности американский ученый особое значение уделял двум взаимосвязанным аспектам: соответствию политических институтов ожиданиям индивидов (социальный уровень) и нормативно-ценностным образцам (культурный уровень). Таким образом, легитимность опирается на санкционированный культурной традищией ценностно-нормативный инвариант, задающий параметры социального порядка. Культурная традиция в данном аспекте выступает в качестве источника власти и может быть определена как «объективно-необходимый способ самоорганизации социальной системы посредством 
ценностно-нормативного упорядочения связей и отношений между ее элементами» [6, с. 98].

Взаимосвязь культурной традиции и власти является онтологически обусловленной и вытекает из их природы: и культурная традиция, и власть, во-первых, представляют собой необходимое, собственно человеческое, средство приспособления к среде обитания и, во-вторых, устанавливают определенные нормы взаимодействия индивидов, обеспечивая тем самым взаимосвязь социальной действительности и ценностей [6, с. 90-91]. Легитимность, таким образом, напрямую связана с признанием норм и регулятивов, источником которых выступает культурная традиция в качестве социально значимых ценностей. Следовательно, ценности в социальной системе выступают надбиологическим, сверхприродным фактором регуляции деятельности, поведения и общения человека, в них фиксируются социально значимые нормы, опираясь на которые «задается целостный образ человеческого жизненного мира, картина этого мира» [7, с. 195]. Признание таких категориальных структур (культурных универсалий) ценностями, образующими базисные параметры интегративного качества социальной системы, представляет собой процесс легитимации установления власти как средства поддержания и воспроизводства социального порядка.

Соответственно, кризис легитимации связан прежде всего с постулированием постидеологического характера социальной реальности, т. е. с отрицанием онтологической природы ценностей, конституирующих основания актуального социального порядка. При этом именно идеология выступает «формой представления картины мира и способом полагания ценностей-норм, регулирующих-упорядочивающих социальное взаимодействие» [6, с. 84]. В трансформирующемся социуме, в котором стремительно увеличивается риск возникновения «редуктивных социальных ситуаций» [1, с. 115], ввиду отсутствия признанной в качестве легитимной системы ценностей, одним из способов осуществления власти и поддержания порядка выступает манипулирование. Распространение репрессивных социальных практик и технологий манипулирования массовым общественным сознанием становится возможным при отсутствии четко фиксированного ценностно-нормативного инварианта, образующего общее символическое и смысловое поле культуры и базирующегося не столько на силе, сколько на достижении согласия («гегемонии»- в терминологии А. Грамши).

При этом, как отмечает отечественный исследователь И. Н. Сидоренко, выявляя взаимосвязь феномена власти с полаганием упорядочивающих социальную структуру ценностей, «несмотря на увеличивающуюся рационализацию жизни, современное информационное общество сталкивается с новой проблемой: тотальность символического насилия, порождающего новые технологии контроля и социальные практики» [8, с. 32]. Таким образом, власть, источником которой выступает культурная традиция, в условиях возрастания роли информационно-коммуникационных технологий в производстве товаров и услуг, объективируется не столько за счет применения исключительно силовых методов сохранения порядка и поддержания гомеостаза социальной системы, сколько путем конституирования общего ценностносмыслового, идеологического пространства. В установлении такого рода власти, которая «навязывает значения, заставляя признать их легитимными и одновременно скрывая силовые отношения, лежащие в ее основе» [8, с. 38], одну из ключевых ролей играет идея «ненасильственного принуждения», в современной социально-философской литературе получившая свое оформление в рамках концепции soft ideology («мягкой идеологии»). В предельном своем выражении речь может идти о формировании социальной реальности как символически конструируемого пространства, в котором идеология хотя имплицитно и структурирует действительность, легитимизируя существующие отношения господства, выступает в роли «неявного знания», через власть языка формируя представления о реальности. Формируя пространство семантической и ценностно-смысловой интерсубъективности, язык как средство репрезентации культурного кода становится одним из механизмов реализации властеотношений, направленных на достижение согласия по поводу ключевых аксиологических ориентаций социума.

Последний аспект детально рассматривается в учении о гегемонии итальянского философа Антонио Грамши. Согласно А. Грамши, источником институционально легитимной власти выступает не столько насилие, сколько согласие индивидов относительно базовых ценностей, упорядочивающих социальную реальность [9, c. 173-174]. Другими словами, основой власти, ее формообразующим фактором является идеология, поскольку экономическое господство автоматически не обеспечивает господство социально-политическое, связанное с достижением достаточного уровня согласия, т. е. гегемонии. Поэтому если основой власти господствующего класса является гегемония, то вопрос поддержания политического порядка и условий его трансформации (слома) перерастает в вопрос о том, как достигается или подрывается гегемония. 
Что касается технологий слома актуального социально-политического порядка, то их А. Грамши связывает с трансформацией «культурного ядра» социальной системы, преобразованиями социокода, аккумулирующего в культурных универсалиях представления о мире и человеке, добре и зле, прекрасном и безобразном и т. Д. Причем эти изменения происходят, прежде всего, на уровне репрезентации социально значимых ценностей, которые получают новую трактовку и смысл, постепенно изменяя мнения и настроения в сознании каждого человека.

«Кризис гегемонии», сопровождающийся идеологической интервенцией в ценностносмысловой пласт культурной традиции, в своем предельном выражении приводит, во-первых, к рождению альтернативной по отношению к легитимно признанной «коллективной воле» и, во-вторых, к конфронтации социальных страт в результате применения технологий манипулятивной семантики и риторики. Предметом воздействия в условиях такой «пассивной революции» выступает прежде всего обыденное сознание, «картина мира» которого на уровне «здравого смысла» как раз и задается ключевыми универсалиями, присущими конкретной культурной традиции. При этом именно «творческое меньшинство» (А. Дж. Тойнби), интеллигенция способны обеспечить трансляцию и воспроизводство референтных ценностей культурной традиции, конституирующих социальный порядок и являющихся источником социальной стабильности. В этой связи А. Грамши главную роль в осуществлении «пассивной революции» отводит интеллигенции, напрямую связывая ее компетенции с установлением определенных, ценностно ангажированных, властных отношений в обществе [9, с. 174].

Таким образом, формирование прежде всего культурной гегемонии является одним из условий успеха «пассивной революции», поскольку последняя предусматривает определенную идеологическую организацию и основанный на ней социально-политический порядок. Поэтому неизменным спутником «пассивной революции» является «символическое информационное насилие», предполагающее «бессознательное подчинение власти посредством системы знания и иерархии ценностей, приобретающих само собой разумеющийся характер» и в пространстве которого, как отмечает И. Н. Сидоренко, «начинают конкурировать различные “сценарии-видения" одного и того же события» [8, с. 38]. Такая глубокая конфронтация социальных сил и выступает источником кризиса легитимации, который, в свою очередь, порождает конкуренцию «картин мира», претендующих на репрезентацию «легитимного видения социальной реальности» (П. Бурдье) [10, с. 78].

В эпоху метамодерна, характеризующуюся среди прочего доминированием не «великих идеологических нарративов», а распространением «повседневных идеологий», призванных, как отмечает Р. Ван ден Аккер, «дать нам смысл и цель (и снизить сложность мира)» [11], а также преодолеть политическую ангажированность культуры, характерную для традиции модерна, процесс легитимации становится зависим от интерпретирующего социальную реальность субъекта, особенностей его когнитивного и интеллектуального оснащения. Как отмечает в этой связи Р. Ван ден Аккер, «вместо создания постоянного набора параметров, который, с одной стороны, определяет мировоззрение и, с другой стороны, исключает любое обсуждение и отклонение от этих параметров, как это происходило в модернизме, политические идеологии метамодерна собирают и отбирают все выброшенное, как нам казалось, в мусорную корзину истории, с целью что-то сказать» [11]. Заново истолкованные культурные универсалии, фундирующие основание «картины социальной реальности», в метамодерне выступают в качестве взаимодополняющих, равно претендующих на признание их легитимными. В таком случае смена мировоззренческих парадигм в ходе «пассивной революции» предстает как процесс фрагментации «коллективной воли», что чревато опасностью возрастания фундаментализма и экстремизма.

Как отмечает автор «The Metamodernist Manifesto» (2011) Люк Тёрнер, будущее культуры - в «прагматическом романтизме, свободном от идеологического крепежа», характерного для модерна, который трактуется как «век идеологической наивности» [12]. Однако с распространением «повседневных идеологий», репрезентирующих мозаичный характер формирующейся цифровой культуры, возрастет влияние экстремистски настроенных движений, претендующих на выражение в «sensus communis» («здравый смысл») «само собой разумеющегося», «очевидного», отражающего реальность «такой, какова она есть на самом деле». Возрастание роли средств массовой информации и коммуникации в легитимации «повседневных идеологий», интенсивное развитие и распространение множества социальных сетей - все это приводит к фрагментации «коллективной воли» и коллективных форм идентичности, непосредственно связанных с системой мировоззренческих представлений и установок, которые фундируют основания культуры. В условиях углубляющегося разрыва «повседневных идеологий», их конфронтации возрастает дивергенция социокультурных систем, что нередко приводит к неприятию 
ценностей других культур, эскалации различных форм насилия и трайбализма.

В «постидеологически» конструируемой социальной реальности, как это вытекает из концепции метамодернизма, индивидуальные и коллективные формы идентичности все в большей степени сводятся к ее символическим измерениям. Власть, призванная легитимизировать ценностно обусловленный социальный порядок, в современную эпоху «постидеологии» выстраивается не как принуждение-насилие и стимулирование, а как манипулирование, прибегая к «управлению посредством идеологического воздействия, оперирования оценками и смыслами» [6, с. 98]. И если постмодерн был ориентирован на формирование игрового сознания и игрового отношения к действительности, что в конечном счете редуцирует институционально организованную власть к инструменту манипулирования индивидуальным и общественным сознанием, то в метамодерне, «существующем между “постмодернистской насмешкой” и “модернистским энтузиазмом"» [13, с. 5], вертикаль власти трансформируется в горизонтально организованные институты влияния. Происходящий в эпоху метамодерна переход от вертикальных систем организации социума к горизонтальным, чему во многом способствует интенсивное развитие IT-инфраструктуры, свидетельствует о смещении властного дискурса к своим неформальным, неинституциональным формам, роль которых в формировании ценностно-нормативной структуры социума становится все более определяющей.

Заключение. В эпоху метамодерна власть реализует себя посредством манипулирования, что находит свое выражение в феномене постидеологической реальности, отражающем совершающийся переход к новому типу общественного устройства - информационному, постиндустриальному. Кризис легитимации в таком обществе становится одним из важнейших индикаторов социальной дивергенции, сопровождающейся, как правило, эскалацией насилия как выражения предельной формы конфронтации и углубления социальных противоречий. В то же самое время возникший кризис признания ценностей и норм в качестве регулятора поведения, общения и деятельности индивидов, или кризис легитимации, часто оказывается конструктивным и способствует переосмыслению исторически сложившейся и закрепленной культурной традицией картины мира, намечая новые потенциально возможные линии динамики культуры. Преобразование социокода в эпоху «пассивной революции» (А. Грамши) становится одновременно имманентным процессом переходного периода в развитии социальной системы и одним из условий конструктивного разрешения накопившихся социальных противоречий и преодоления кризиса.

\section{Список литературы}

1. Мамардашвили М. Вильнюсские лекции по социальной философии (Опыт физической метафизики). СПб.: Азбука, 2012. 320 с.

2. Рикёр П. Политика, экономика, общество. Рукописи и выступления; пер. с фр. И. С. Вдовиной. М.: Центр гуманитарных инициатив, 2021. 240 с.

3. Момджян К. Х. Социальная философия. Деятельностный подход к анализу человека, общества, истории. М.: Изд-во Моск. ун-та, 2013. 398 с.

4. Алексеева Т. А. Легитимность // Новая философская энциклопедия: в 4 т. / Ин-т философии Рос. акад. наук. М., 2010. Т. 3. С. 384.

5. Парсонс Т. О социальных системах. М.: Акад. проект, 2002. 831 с.

6. Голубев С. В. Идеология и государственность: теория и практика. М.: Спутник+, 2018. 215 с.

7. Степин В. С. Теоретическое знание. М.: Прогресс-Традиция, 2000. 744 с.

8. Сидоренко И. Н. Философия насилия: от метафоры к концепту. Минск: БГУ, 2017. 175 с.

9. Грамши А. Искусство и политика: в 2 т.; пер. с итал. М.: Искусство, 1990-1991. Т. 1. 1991. 432 с.

10. Бурдье П. Социология социального пространства; пер. с фр. М.: Ин-т эксперим. социологии; СПб.: Алетейя, 2007. 288 с.

11. Интервью с Робином ван ден Аккером [Электронный ресурс] // Metamodern - Журнал о метамодернизме. URL: http://metamodernizm.ru/robin-van-den-akker/ (дата обращения: 01.03.2021).

12. Luke Turner. The Metamodernist Manifesto [Electronic resource] // Metamodernist - Manifesto. URL: http://www.metamodernism.org/ (access date: 01.03.2021).

13. Павлов А. В. Образы современности в XXI веке: метамодернизм // Логос. 2018. Т. 28 , № 6. C. 1-19.

\section{References}

1. Mamardashvili M. Vil'nyusskiye lektsii po sotsial'noy filosofii (Opyt fizicheskoy metafiziki) [Vilnius Lectures on Social Philosophy (Experience in Physical Metaphysics)]. St. Petersburg, Azbuka Publ., 2012, 320 p. 
2. Rikyo P. Politika, ekonomika, obshchestvo. Rukopisi i vystupleniya [Politics, economics, society. Manuscripts and speeches]. Moscow, Tsentr gumanitarnykh initsiativ Publ., 2021. 240 p.

3. Momdzhyan K. Kh. Sotsial'naya filosofiya. Deyatel'nostnyy podkhod k analizu cheloveka, obshchestva, istorii [Social philosophy. An activity-based approach to the analysis of a person, society, history]. Moscow, Izdatel'stvo Moskovskogo universiteta Publ., 2013. 398 p.

4. Alekseeva T. A. Legitimacy. Novaya filosofskaya entsiklopediya: $v 4$ tomakh [New philosophical encyclopedia: in 4 vol.]. Moscow, 2010, vol. 3, p. 384 (In Russian).

5. Parsons T. O sotsial'nykh sistemakh [About social systems]. Moscow, Akademicheskiy proyekt Publ., 2002. $831 \mathrm{p}$.

6. Golubev S. V. Ideologiya i gosudarstvennost': teoriya i praktika [Ideology and statehood: theory and practice]. Moscow, Sputnik+ Publ., 2018. 215 p.

7. Stepin V. S. Teoreticheskoye znaniye [Theoretical knowledge]. Moscow, Progress-Traditsiya Publ., 2000. $744 \mathrm{p}$.

8. Sidorenko I. N. Filosofiya nasiliya: ot metafory k kontseptu [Philosophy of Violence: From Metaphor to Concept]. Minsk, BGU Publ., 2017. 175 p.

9. Gramshi A. Iskusstvo i politika: $v 2$ tomakh [Art and politics: in 2 vol.]. Moscow, Iskusstvo Publ., 1990-1991. Vol. 1. 1991. 432 p.

10. Burd'e P. Sotsiologiya sotsial'nogo prostranstva [Sociology of social space]. Moscow, Institut eksperimental'noy sotsiologii Publ.; St. Petersburg, Aleteyya Publ., 2007. 288 p.

11. Interview with Robin van den Acker. Metamodern - Zhurnal o metamodernizme [Metamodern Journal of metamodernism]. 2021. Available at: http://metamodernizm.ru/robin-van-den-akker (accessed 01.03.2021).

12. Luke Turner. The Metamodernist Manifesto. Metamodernist - Manifesto [Metamodernist - Manifesto]. Available at: http://www.metamodernism.org (accessed 01.03.2021).

13. Pavlov A. V. Images of modernity in the XXI centure: metamodernism. Logos [Logos], 2018, vol. 28, no. 6, pp. 1-19 (In Russian).

\section{Информация об авторе}

Колядко Илья Николаевич - кандидат философских наук, доцент кафедры философии и методологии науки. Белорусский государственный университет (220030, г. Минск, пр-т Независимости, 4, Республика Беларусь). E-mail: kaliadka@bsu.by

\section{Information about the author}

Kolyadko Il'ya Nikolaevich - PhD (Philosophy), Associate Professor, the Department of Philosophy and Methodology of Science. Belarusian State University (4, Nezavisimosti Ave., 220030, Minsk, Republic of Belarus). E-mail: kaliadka@bsu.by 